\title{
Mentoring for new consultants
}

\author{
${ }^{1} \mathrm{R}$ Ackroyd , ${ }^{2} \mathrm{KA}$ Adamson \\ ${ }^{1}$ Consultant in Palliative Medicine, Calderdale Royal Hospital, Halifax, UK; ${ }^{2}$ Consultant Physician, St John's Hospital, Livingston, UK
}

\begin{abstract}
There is increasing evidence of the benefits of having a mentor during the early years as a consultant. Mentoring encourages and provides support to an individual in their professional development. Although there are different forms of mentoring there is recognition that developing a formal mentoring scheme can provide a consistent approach and support within a framework. The Royal College of Physicians of Edinburgh has introduced a mentoring scheme for new consultants that provides a forum for supporting them in their ongoing professional wellbeing. There is potential that the process of mentoring can improve an individual's development, and motivate and encourage them to develop the skills needed to achieve their goals, thus having an impact on ultimately improving their ability to deliver an effective patient-centred service.
\end{abstract}

Correspondence to R Ackroyd Calderdale and Huddersfield NHS Foundation Trust Macmillan Unit Calderdale Royal Hospital Salterhebble Halifax HX3 OPW UK

e-mail jeena.ackroyd@cht.nhs.uk

KEYWORDS mentee, mentor, mentoring, professional development

DECLARATION OF INTERESTS No conflict of interests declared

\section{INTRODUCTION}

Historically 'mentoring' is not a new concept. In Greek mythology, Telemachus, the son of Odysseus, was guided by a man named Mentor' and, in the medical world, Sir William Osler was viewed as a mentor to the neurosurgeon Dr Harvey Cushing. ${ }^{2}$ The term 'mentor' and the idea of having a guide to help an individual get through their first few years as a new consultant is inviting. The non-clinical components can be particularly daunting if there has been minimal exposure as a trainee. As the NHS continues to change, consultants need to be adaptable and resilient. With increasing standards to achieve and targets to meet while trying to provide evidence of good medical practice for revalidation, it is not surprising that there is increasing recognition that mentoring is an effective model to ease the transition from trainee to established consultant. ${ }^{3}$ Mentoring may help manage change ${ }^{4}$ and lessen stress. ${ }^{5}$

In the medical profession, mentoring has been available for all - from medical students ${ }^{6,7}$ to qualified doctors. ${ }^{3,6}$ It has also been introduced for specific specialties such as general practice, ${ }^{5,8}$ psychiatry ${ }^{9}$ and surgery. ${ }^{10,11}$ However, despite increasing recognition of the benefits of mentoring in medicine, ${ }^{12-14}$ and national recommendations, ${ }^{3,15}$ mentoring schemes are still not available consistently, with dependency on what local areas deliver.

\section{WHAT IS MENTORING?}

There are different definitions of mentoring in the literature. The Standing Committee on Postgraduate
Medical and Dental Education described mentoring as 'the process whereby an experienced, highly regarded empathic person (the mentor) guides another individual (the mentee) in the development and re-examination of their own ideas, learning, and personal and professional development'. ${ }^{15}$ For new consultants who will be the mentee, the mentor will be an established consultant, usually with at least five years experience or who may have retired. The relationship is voluntary, confidential and professional. Mentoring should be viewed as a positive mechanism of support to all fledgling consultants and not only for consultants who feel they are not coping or are failing in their role. ${ }^{10}$

\section{PURPOSE OF MENTORING}

The aim of mentoring is to support and develop an individual in their professional development and personal wellbeing. ${ }^{8}$ It is a process of empowering an individual to discover their hidden potential and achieve their goals ${ }^{16}$ and encourage them to make their own decisions. At the core of mentoring is the understanding that the mentor should avoid the temptation to tell the mentee what to do or give advice. ${ }^{10,17}$ This can be quite hard for senior clinicians who are used to making decisions and taking control. ${ }^{17,18}$

Mentoring should not be confused with other methods of support within medicine such as coaching and counselling, and is separate to assessment and appraisal. ${ }^{19}$

\section{TYPES OF MENTORING}

With the increasing evidence that mentoring can be beneficial, the question is how best to provide it. 


\section{Informal mentoring}

Informal mentoring is part of the traditional support which has been happening under the radar for years in medicine, tending to occur between peers on an ad hoc basis and which Bligh defined as being largely invisible. ${ }^{20}$ Informal mentoring may be more costeffective as there are fewer resources needed, but is more difficult to evaluate and standardise ${ }^{17}$ and relies on being initiated by the mentee. ${ }^{17,21}$ However, potential mentees may be reluctant to seek out mentoring and with this method the chance of getting effective mentoring is unpredictable. ${ }^{10}$

\section{Formal mentoring}

A formal mentoring programme can provide a more structured and consistent approach, by clearly defining the roles and responsibilities of both the mentor and mentee. ${ }^{8}$ There can also be formalised support for the mentors, especially if there are experienced mentors leading the programme, so that mentors can get advice if needed. ${ }^{22}$ Driessen et al. ${ }^{23}$ describe different formal mentoring formats including the mentor-is-appointed model where the mentee is allocated a mentor, and the mentor-on-demand model when there are trained mentors who are available for mentoring; so although the onus is on the mentee to choose, they are signposted to particular individuals.

To facilitate this, biographies of mentors can be provided and schemes can also specifically approach potential mentees. This is particularly useful for mentees who have struggled to find mentors on their own. ${ }^{16}$ Administrative help in coordination is also useful to facilitate the mentoring selection. However there are funding implications in sustaining mentoring schemes and providing administrative support, and for the amount of time that needs to be invested for a successful programme to remain embedded within an organisation.

\section{BENEFITS OF MENTORING}

There are specific benefits to the mentee but also to the mentor and to the wider organisation. If mentors and mentees feel more valued and secure within their jobs then this could lead to better care provision and indirectly contribute to the quality of the healthcare delivered (Table I).

\section{CHARACTERISTICS OF AN EFFECTIVE MENTOR: COULD YOU BE A MENTOR?}

For a good mentoring relationship to work, it is apparent that a mentor needs to be committed, have a genuine interest in the development of others ${ }^{10}$ and be willing to invest the time to do $\mathrm{it}^{24}$ (Table 2 ).

\begin{tabular}{|c|c|c|}
\hline Mentee & Mentor & Organisation \\
\hline $\begin{array}{l}\text { Increased job } \\
\text { satisfaction }\end{array}$ & $\begin{array}{l}\text { Ability to } \\
\text { transfer skills to } \\
\text { use with patients, } \\
\text { relatives and } \\
\text { colleagues }\end{array}$ & $\begin{array}{l}\text { Increased staff } \\
\text { retention }{ }^{13}\end{array}$ \\
\hline $\begin{array}{l}\text { Greater self- } \\
\text { confidence in } \\
\text { their own } \\
\text { ability }^{29,36}\end{array}$ & $\begin{array}{l}\text { Sharing of } \\
\text { experience and } \\
\text { learning }\end{array}$ & $\begin{array}{l}\text { Improved service } \\
\text { provision }{ }^{4,30}\end{array}$ \\
\hline $\begin{array}{l}\text { Improved } \\
\text { objectivity with } \\
\text { problem solving }\end{array}$ & $\begin{array}{l}\text { Personal } \\
\text { satisfaction from } \\
\text { helping others }{ }^{3} \\
\end{array}$ & Valued workforce ${ }^{17}$ \\
\hline $\begin{array}{l}\text { Improved ability } \\
\text { to implement } \\
\text { change }^{8,14}\end{array}$ & $\begin{array}{l}\text { Increased } \\
\text { professional } \\
\text { development }^{8}\end{array}$ & $\begin{array}{l}\text { Improved motivation } \\
\text { and performance of } \\
\text { staff }^{4}\end{array}$ \\
\hline \multicolumn{3}{|l|}{$\begin{array}{l}\text { Improved work- } \\
\text { life balance }\end{array}$} \\
\hline $\begin{array}{l}\text { Increased self- } \\
\text { effectiveness }^{16}\end{array}$ & & \\
\hline
\end{tabular}

TABLE 2 Characteristics of a good mentor $4,17,24$
\begin{tabular}{|l|l|}
\hline Approachable & Role model \\
\hline Genuinely interested in others & Sounding board \\
\hline Effective listener & Enthusiastic \\
\hline $\begin{array}{l}\text { Willing to be challenged and be } \\
\text { challenged }\end{array}$ & Non-judgmental \\
\hline Passion for developing others & Facilitator \\
\hline Constructive & Encouraging \\
\hline
\end{tabular}

\section{SKILLS FOR MENTORING}

When considering what the mentorship relationship encompasses it is no surprise that mentors need to build on their existing communication skills. The core skills include: active listening, ${ }^{3}$ questioning, promoting critical reflection, and delivering constructive feedback. Active listening is the skill of completely listening to an individual without distraction ${ }^{25}$ and, combined with asking appropriate questions, encourages reflection and learning from experience. ${ }^{17,26}$

Having the ability to balance between being supportive while also being able to know when to gently challenge is useful. $13,22,27$ Providing constructive feedback in a nonthreatening way is also crucial to help mentees identify for themselves what they need to do to achieve their goals. ${ }^{17}$ To consolidate these skills, mentoring training is recommended $d^{19,23}$ and can provide a consistent approach.

\section{WHAT IS EXPECTED FROM THE MENTEE?}

Mentoring should be mentee-centred and be focused on the mentee's agenda. ${ }^{5}$ But there is an expectation that 
mentees be engaged in the process. Although the mentor will manage the overriding relationship the mentee should drive it with what their goals are and what objectives they would like to focus on.

\section{The mentoring meeting}

Initially it is useful for the meeting to be face-to-face in a neutral environment and this also helps build rapport. A mentoring contract is helpful to clarify roles. Ground rules are recommended at the first meeting with the mentor setting the boundaries with regard to expectations ${ }^{27}$ and duration and frequency of meetings. In the first year it is helpful if there are regular set times with meetings occurring every $2-3$ months. After the first year, meetings may take place less frequently as and when the mentee needs the mentor and may be supported with email or telephone advice. ${ }^{17}$ The overall relationship is finite with a typical timeframe being two years. Utilising a framework to structure the meeting can be helpful.

\section{The process of mentoring}

A useful framework to structure each mentoring conversation is the 3-stage model, adapted from the 'skilled helper model'25 and those stages are: exploration, new understanding, and action planning (Figure I). ${ }^{28}$

Exploration Initially the mentor takes the lead by using open questions and active listening is predominantly used so the mentee is encouraged to talk about what is concerning them. There is an element of fact finding as the mentor finds out what they need to focus on $^{5}$ and clarify what the mentee's goals are.

New understanding $A t$ this stage the mentor has confirmed which issues are important to the mentee. The mentee is encouraged to reflect and priorities are established. Constructive feedback may also be given and this should facilitate the mentee into starting to see things in different ways and decide what to do next.

Action planning Once a mentee has identified what they need to do, specific objectives can be set to achieve their goals with the mentor's encouragement.

\section{DEVELOPING A FRAMEWORK}

With less opportunity for informal mentoring there has been a move towards more formal schemes. ${ }^{3}$ This widens the choice and opportunities for mentees to find a mentor. Implementing a formal framework does require senior support and a designated lead. ${ }^{19}$ This method allows a system of matching using a third party. It ensures there are enough mentors available and mitigates the need for the mentee having to actively find someone suitable. Through promotion, the scheme may also be able to reach out to individuals who may not have considered that they

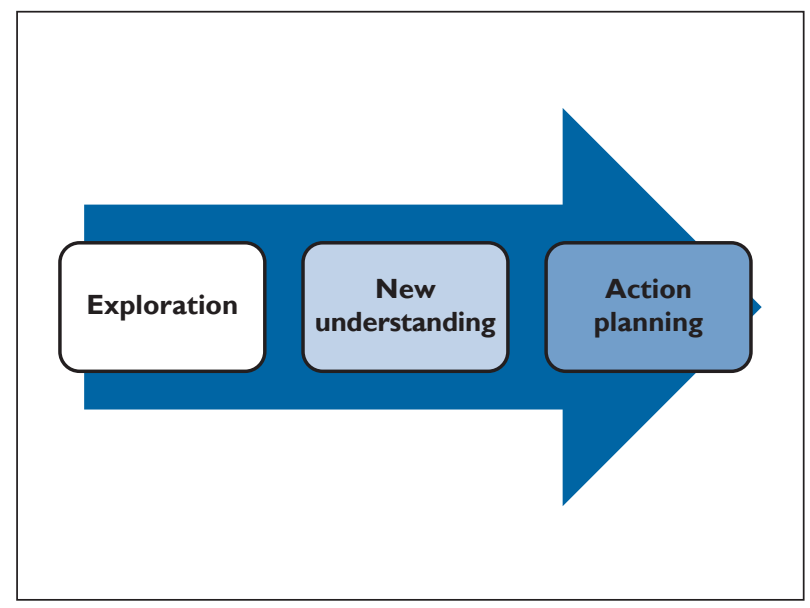

FIGURE I The 3-stage mentoring process. Adapted from Alred G, Garvey B. Mentoring Pocketbook. 3rd ed. Alresford, Hants: Management Pocketbooks; 2010.

would benefit from mentoring. Qualitative and quantitative evaluation is also important. ${ }^{29}$

\section{CHALLENGES TO MENTORING}

Despite the benefits of mentoring, it is important to be aware of the potential difficulties that could occur. Unrealistic expectations on either side can affect the relationship and this can be avoided by ensuring that the objectives of mentoring are clearly outlined and explained to both mentors and mentees ${ }^{30}$ who need to understand what is expected of them and have well defined roles and responsibilities. There should also be clear boundaries to the relationship which will help alleviate the risk of poor mentoring. ${ }^{31}$ Identifying mentors who have the key skills is imperative to avoid the potential of 'toxic mentoring.'

Although personal concerns do impact on professional development a mentee should not become dependent on the mentor and it is vital that the mentor does not become a 'therapist' but should be aware of when to signpost the mentee elsewhere. ${ }^{22}$ There should also be transparency within the programme so that, if a match is not working, the 'contract' can end and the mentee can ask for a different mentor.

There is always concern that time constraints can affect a mentoring relationship $\mathrm{p}^{33}$ and this does need to be addressed within schemes to ensure mentors are committed, and reinforces the importance of putting careful consideration into the planning process. Ideally there should be time made within job plans to allow for mentoring.

\section{SUPPORTING MENTORS}

It is important that mentors do not feel isolated and that they feel supported to avoid any feeling of vulnerability 
or anxiety. ${ }^{8} \mathrm{~A}$ structured process as outlined can help the mentor navigate and provide the route to take at each mentoring meeting. Peer feedback sessions with other mentors can encourage mentors to reflect on their performance, share experiences and provide peer support. ${ }^{13}$

\section{WHAT IS HAPPENING NATIONALLY?}

There are numerous mentoring initiatives across the UK. Many trusts will have their own mentoring scheme that newly appointed consultants can opt into. In addition, there are specialty based schemes such as the National Diabetes Consultant Mentoring Program, administered by the Association of British Clinical Diabetologists. ${ }^{34}$ At a college level, the Royal College of Physicians and Surgeons of Glasgow has a wellestablished scheme. ${ }^{35}$

At the Royal College of Physicians of Edinburgh, a call for mentors occurred in November 2014. Potential mentors undergo a half day of structured training as an opportunity to consolidate and practice the skills needed for the role. Three training sessions have been held with more planned and a call for mentees occurred at the beginning of 2015 .

Different schemes will have differing time implications. This should be made explicit at the start. The key is that it should be driven by the needs of the mentee. Trust based schemes will, by their nature, be an integral part of an individual's job plan, and incorporated into supporting professional activities (SPA) time. For schemes at a more national level, time in job plans is less defined. For the RCPE scheme, we would envisage this would be incorporated into time spent on college activities, and as such time in job plans will be allocated according to trust policy.

\section{CONCLUSION}

Building on the increasing evidence of the benefits of mentoring is ensuring that consultants have access to mentoring and choose the most appropriate scheme for them. The benefits to the mentor and their organisations should also not be ignored. From a mentor's perspective, mentoring can be extremely rewarding but can also transform the culture of the organisation where mentoring is taking place. More research into the advantages to mentors would be insightful and encourage more potential mentors to come forward, particularly as the skills used as a mentor can be transferred to their normal working day with regard to relationships with colleagues and patients. ${ }^{13}$

There is always the concern that with continuing difficulties in trying to balance clinical commitments with the declining time for supporting professional activities that mentoring is viewed as a luxury and not a necessity. However, developing doctors who are more empowered and satisfied in their job is a reason to ensure mentoring gets its recognition. Mentoring can help new consultants to face the challenges of providing healthcare in a changing environment with more confidence and resilience. Mentoring provides the tools needed to equip mentees to lay the foundations they need to build their future. This can benefit the organisation they work in and ultimately improve their patient care while also encouraging them to become the next generation of mentors. 


\section{REFERENCES}

I Homer. The Odyssey. CreateSpace Independent Publishing Platform; 2013.

2 Duffy TP.The Osler-Cushing covenant. Perspect Biol Med 2005; 48 : 592-602.

3 Department of Health. Mentoring for doctors. Signposts to current practice for career grade doctors. Guidance from the Doctors' Forum. 2004. http://bit.ly/IEn75le (accessed 2I/4/20I5).

4 Dancer JM. Mentoring in Healthcare: theory in search of practice? Clinician in Management 2003; 12: 21-31.

5 Alliott R. Facilitatory mentoring in General practice. BMJ 1996; 31 3: S2-7060. http://dx.doi.org/I0.I I36/bmj.3 3 3.7060.2

6 Buddeberg-Fischer B, Herta KD. Formal mentoring programmes for medical students and doctors - a review of the Medline literature. Med Teach 2006; 28: 248-57.

7 Fei E, Stamm M, Buddeberg-Fischer B. Mentoring programs for medical students - a review of the PubMed literature 2000-2008. BMC Medical Education 20 I0; 10:32. http://dx.doi.org//0. I I86//4726920-10-32

8 Freeman R. Towards effective mentoring in General Practice. $\mathrm{Br}$ J Gen Pract 1997; 47: 457-60.

9 Royal College of Psychiatrists. West Midlands Division Mentoring Scheme.http://www.rcpsych.ac.uk/workinpsychiatry/divisions/ westmidlands/mentoringscheme.aspx (accessed 28/2/I5).

10 Memon B, Memon MA. Mentoring and surgical training: a time for reflection! Adv Health Sci Educ Theory Pract 20 I0; 15: 749-54. http:// dx.doi.org/ I0.1007/s 10459-009-9/57-3

II Jaffer U, Pennell A, Musonda P. General Surgical Trainee Experiences of Mentoring: A UK Regional Audit. J Surg Educ 2010; 67: 19-24. http://dx.doi.org/I0.10 I6/j.jsurg.2009.10.004

12 Sackin P, Barnett M, Eastaaugh A et al. Peer supported learning. $\mathrm{Br}$ J Gen Pract 1997; 47: 67-8.

13 Connor MP, Bynoe AG, Redfern $\mathrm{N}$ et al. Developing senior doctors as mentors: a form of continuing professional development. Report of an initiative to develop a network of senior doctors as mentors: 1994-99. Med Educ 2000; 34: 747-53.

14 Steven A, Oxley J, Fleming WG. Mentoring for NHS doctors: perceived benefits across the personal-professional interface. J $R$ Soc Med 2008; 10I: 552-7. http://dx.doi.org/I0.1258/ jrsm.2008.080I53

15 Standing Committee on Postgraduate Medical and Dental Education. Supporting doctors and dentists at work: an inquiry into mentoring. London: SCOPME; 1998

I6 Feldman MD, Arean PA, Marshall SJ et al. Does mentoring matter: results from a survey of faculty mentees at a large health sciences university. Med Educ Online 2010; I5. http://dx.doi.org//0.3402/ meo.vI5i0.5063

17 Taherian K, Shekarchian M. Mentoring for doctors. Do its benefits outweigh its disadvantages? Med Teach 2008; 30: e95-9. http://dx. doi.org/I0.1080/0I42I59080I929968
8 Overeem K, Driessen EW, Arah OA et al. Peer mentoring in doctor performance assessment: strategies, obstacles and benefits. Med Educ 20I0; 44: 140-7. http://dx.doi. org/I0.I I I I/j.I 365-2923.2009.03580.x

19 Viney R, McKimm J. Mentoring. Br J Hosp Med 2010; 7I: I06-9.

20 Bligh J. Mentoring: an invisible support network. Med Educ 1999; 33: 2-3.

21 Souba W. Mentoring young academic surgeons, our most precious asset.J Surg Res 1999; 82: II3-20.

22 Romani S, Gruppen L, Krajic Kachur EK. Twelve tips for developing effective mentors. Med Teach 2006; 28: 5; 404-8.

23 Driessen EW, Overeem K, Vanc der Vleuten CP. Get yourself a mentor. Med Educ 20II; 45: 438-9. http://dx.doi. org/I0.I I I I/j.I365-2923.20II.03948.x

24 Darling LAW.What do nurses want in a mentor? J Nurs Adm I984; 14: $42-4$.

25 Egan G. The Skilled Helper. A Problem-Management and OpportunityDevelopment Approach to Helping. 9th ed. International edition: Brooks/Cole; 2009

26 Kolb DA. Experiential Learning: Experience as the Source of Learning and Development. New Jersey: Prentice-Hall; 1984

27 Macleod S. The challenge of providing mentorship in primary care. Postgrad Med J 2007; 83: 317-319.

28 Alred G, Garvey B. Mentoring Pocketbook. 3rd ed. Alresford, Hants: Management Pocketbooks; 2010.

29 Iverson AC, Eady AJ, Wessely SC. The role of mentoring in academic career progression: a cross-sectional survey of the Academy of Medical sciences mentoring scheme.J R Soc Med 20I4; 107: 308-17.

30 Driessen EW, Overeem K. Mentoring. In: Walsh K, editor. Oxford Textbook of Medical Education.Oxford: Oxford University Press; 20I3. p.265-84.

31 Long J. The dark side of mentoring. AARE Conference Newcastle, 1994. http://www.aare.edu.au/data/publications//994/longj94030. pdf (accessed 24/I/20I5).

32 Darling LA. What to do about toxic mentors. Nurse Educ 1986; I I: 29-30.

33 Sambunjak D, Straus SE, Marusić A. Mentoring in academic medicine: a systematic review. JAMA 2006; 296: I I03-I5.

34 Association of British Clinical Diabetologists. National Diabetes Consultant Mentorship Programme. http://www.diabetologists-abcd. org.uk/NDCMP.htm (accessed 2/3/20I5)

35 Royal College of Physicians and Surgeons of Glasgow. Mentorship Programme. https://www.rcpsg.ac.uk/membership/mentorshipprogramme.aspx (accessed 2/3/20I5)

36 Stamm M, Buddeberg-Fischer B. The impact of mentoring during postgraduate training on doctors' career success. Med Educ 201 I; 45: 488-96. http://dx.doi.org/ I0. I I I I/j.I365-2923.20 I0.03857.x 